\title{
Sinus pericranii in a young adult with chronic headache
}

\author{
Raya Saba, ${ }^{1}$ Mourad H Senussi, ${ }^{1}$ Ahmad Alwakkaf, ${ }^{1}$ Harry Brown ${ }^{2}$
}

${ }^{1}$ Department of Internal Medicine, Saint Joseph Hospital, Chicago, Illinois, USA ${ }^{2}$ Department of Diagnostic Radiology, Saint Joseph Hospital, Chicago, Illinois, USA

\section{Correspondence to}

Dr Mourad H Senussi, mouradsenussi@gmail.com

\section{DESCRIPTION}

An 18-year-old-man, with no relevant medical history, presented to the outpatient clinic for the evaluation of chronic headache. The patient described a waxing waning pressure sensation in the occipital area that had started a few months prior, and was slowly progressing in severity. The patient denied any head trauma, exacerbating factors or associated symptoms. He did not use

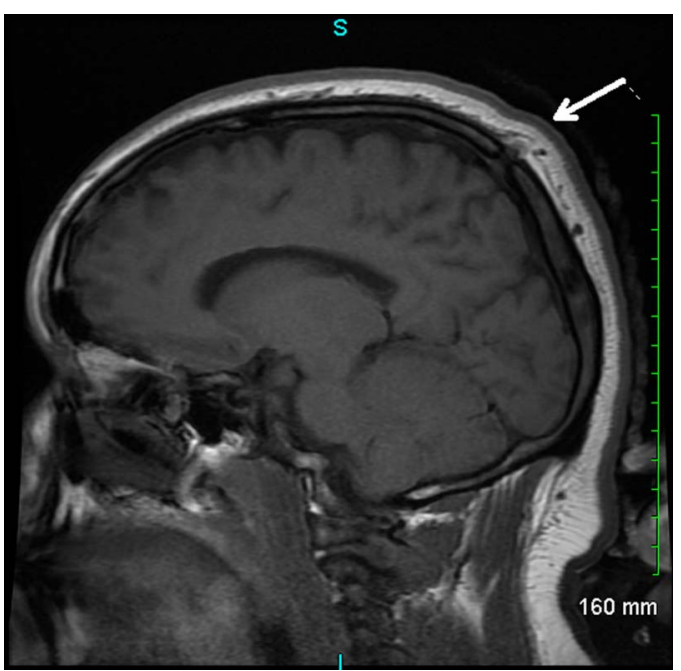

Figure 1 MRI of the brain showing a prominent extracranial scalp vein in direct communication with the superior sagittal sinus through a calvarial defect. tobacco, alcohol or illicit drugs. Family history was non-contributory, and medications included occasional use of over the counter analgesics, with only partial relief of the pain. No apparent scalp abnormalities on inspection, or tenderness on palpation. Physical examination, including neurological examination, was non-focal. Laboratory studies including complete blood count and comprehensive metabolic panel, were normal.

MRI of the brain showed a prominent extracranial scalp vein in direct communication, through a calvarial defect, with the superior sagittal sinus (figures 1 and 2). MR angiography showed normal anterior and posterior circulation, with no evidence of aneurysm, arteriovenous malformation or highgrade stenosis. Radiological findings were consistent with sinus pericranii.

First described in $1850,{ }^{1}$ sinus pericranii is a congenital or acquired disorder characterised by extracranial vascular lesions with anastomotic connections to an intracranial dural sinus. ${ }^{2}$

Patients are usually asymptomatic, or present with vague symptoms such as headache, nausea and vertigo. Treatment is commonly pursued for cosmetic reasons. ${ }^{3}$ However, surgical correction has been advised to prevent rare complications, such as haemorrhage, infection or emboli. ${ }^{4}$ Although a rare entity, sinus pericranii should be considered as a cause of non-specific chronic headache in young adults, with normal physical and laboratory findings.
To cite: Saba $R$, Senussi MH, Alwakkaf A et al. BMJ Case Rep Published online: [please include Day Month Year] doi:10.1136/bcr-2013010165

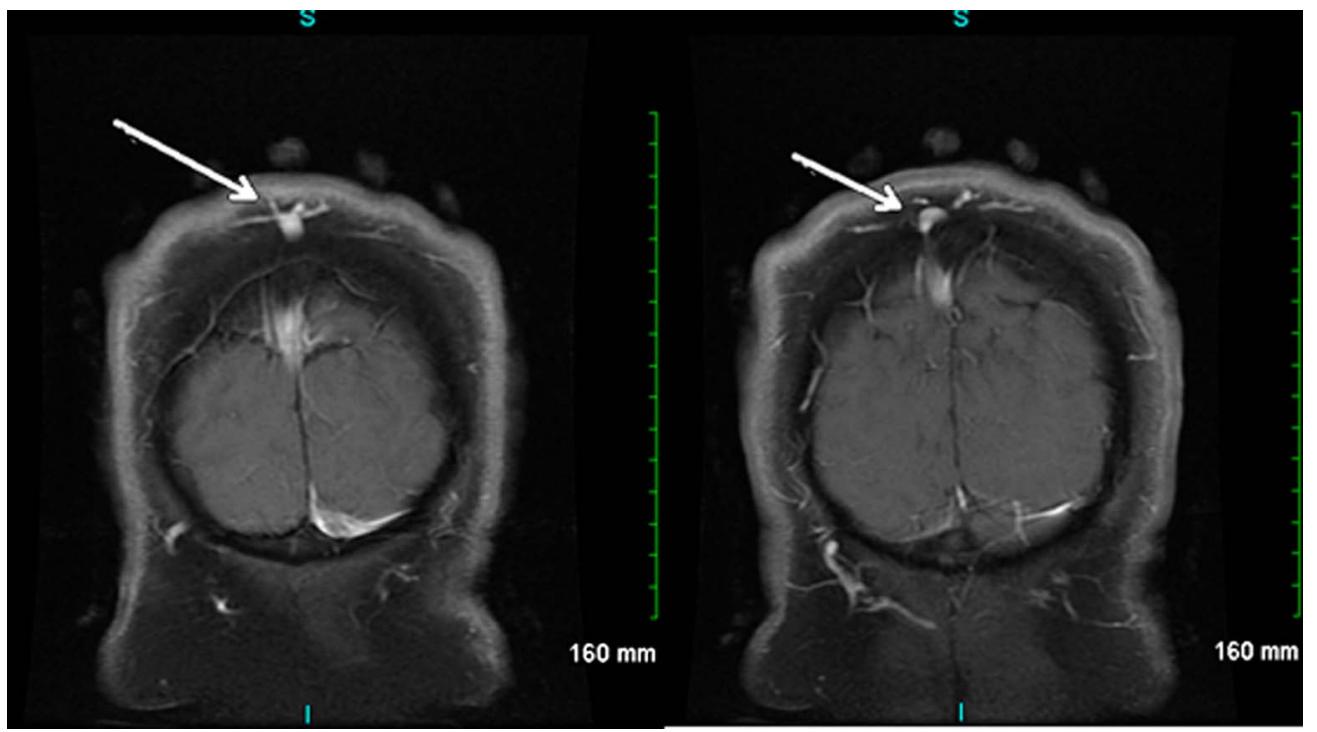

Figure $2 \mathrm{MRI}$ of the brain showing a prominent extracranial scalp vein in direct communication with the superior sagittal sinus through a calvarial defect. 


\section{Learning points}

- Sinus pericranii is a congenital or acquired disorder characterised by extracranial vascular lesions with anastomotic connections to an intracranial dural sinus.

- Sinus pericranii is usually asymptomatic but can present with chronic headache, nausea, vertigo, haemorrhage or infection.

- Although a rare entity, sinus pericranii should be considered as a cause of non-specific chronic headache in young adults, with normal physical and laboratory findings.
Competing interests None.

Patient consent Obtained.

Provenance and peer review Not commissioned; externally peer reviewed.

\section{REFERENCES}

1 Stromeyer. About sinus pericranii. Surg Neurol 1993;40:3-4.

2 Ota T, Waga S, Handa H, et al. Sinus pericranii. J Neurosurg 1975;42:704-12.

3 Gandolfo C, Krings T, Alvarez $\mathrm{H}$, et al. Sinus pericranii: diagnostic and therapeutic considerations in 15 patients. Neuroradiology 2007;49:505-14.

4 Sheu M, Fauteux G, Chang $H$, et al. Sinus pericranii: dermatologic consideration and literature review. J Am Acad Dermatol 2002;46:934-41.

Copyright 2013 BMJ Publishing Group. All rights reserved. For permission to reuse any of this content visit http://group.bmj.com/group/rights-licensing/permissions.

BMJ Case Report Fellows may re-use this article for personal use and teaching without any further permission.

Become a Fellow of BMJ Case Reports today and you can:

- Submit as many cases as you like

- Enjoy fast sympathetic peer review and rapid publication of accepted articles

- Access all the published articles

- Re-use any of the published material for personal use and teaching without further permission

For information on Institutional Fellowships contact consortiasales@bmjgroup.com

Visit casereports.bmj.com for more articles like this and to become a Fellow 